\title{
EFEKTIVITAS PEMBERIAN DOSIS TINGGI METHYLPREDNISOLONE PADA TRAUMA SPINAL CORD AKUT
}

\author{
Abdul Qodir \\ Email: doel qodir09@yahoo.com \\ Prodi Ilmu Keperawatan STIKES Widyagama Husada
}

\begin{abstract}
Acute spinal cord injury is a devastating condition typically affecting young people, mostly males. High-Dose Methylprednisolone treatment in the early hours after the injury is aimed at reducing the extent of permanent paralysis during the rest of the patient's life. The aim To review randomized trials of High-Dose Methylprednisolone in Acute Spinal Cord Injuries. All randomized controlled trials of steroid treatment for acute spinal cord injury in any language. Data have been extracted from original trial reports. For the NASCIS, Japanese and French trials, additional data (e.g. SDs) have been obtained from the original authors. The evidence produced by this systematic review support the use of high dose methylprednisolone in acute spinal cord injury to improve neurological recovery. Patients who received high-dose methylprednisolone therapy should be observed with intensive in order to reduce complications from such therapy.
\end{abstract}

Keywords: Acute spinal cord, Injury, and Methylprednisolone 


\begin{abstract}
ABSTRAK
Cedera tulang belakang akut adalah suatu kondisi yang menyebabkan kecacatan pada orang-orang muda, kebanyakan laki-laki. Terapi dosis tinggi methylprednisolone secara dini setelah cedera bertujuan untuk mengurangi tingkat kelumpuhan permanen selama sisa hidup pasien. Tujuan dari makalah ini adalah untuk meninjau percobaan acak dari High-Dosis Methylprednisolone Akut Spinal Cord Cedera. Semua penelitian dengan desain randomized controlled trials dari pengobatan steroid untuk cedera tulang belakang akut dalam bahasa apapun. Data telah dianalisa dari laporan percobaan asli. Untuk NASCIS, Jepang dan Perancis percobaan, data tambahan (misalnya SD) telah diperoleh dari penulis asli. Bukti yang dihasilkan oleh tinjauan sistematis ini mendukung penggunaan dosis tinggi metilprednisolon pada trauma spinal cord fase akut untuk meningkatkan pemulihan neurologis. Pasien yang menerima terapi metilprednisolon dosis tinggi harus diamati dengan intensif untuk mengurangi komplikasi dari terapi tersebut.

Kata Kunci: Cedra, Tulang Belakang, dan Methylprednisolone
\end{abstract}

\section{PENDAHULUAN}

\section{Latar Belakang}

Diperkirakan angaka kejadian spinal cord injury (SCI) adalah sekitar 40 kasus per juta penduduk di AS atau sekitar 12.000 kasus baru setiap tahun, tidak termasuk korban yang meningal di tempat kejadian. Wyndaele dan Wyndaele (2006) melaporkan bahwa insiden cedera spinal secara global bervariasi dengan kisaran 10.4 sampai dengan 83 kasus per juta populasi setiap tahun (Furlan and Fehlings, 2009). Penyabab yang paling sering dari spinal cord injury (SCI) sejak tahun 2005 adalah kecelakan kendaraan bermotor $(42 \%)$, jatuh, kekerasan (terutama luka tembak) dan olahraga. Insiden spinal cord injury (SCI) lebih besar terjadi pada dewasa muda, dari seluruh korban spinal cord injury (SCI) sekitar $80 \%$ adalah usia 40 tahun (Kelly A. at.al., 2010).

Spinal cord injury merupakan salah satu penyebab utama disabilitas neurologis akibat trauma. Kerusakan neurologi dapat disebabkan oleh cedera primer atau cedera sekunder. Cedera primer diakibatkan oleh traksi dan kompresi pada medula spinalis, baik oleh tonjolan/fragmen tulang, herniasi diskus vertebralis maupun ligamen. Cedera sekunder dapat mengakibatkan ischemia, perubahan elektrolit, respon inflamasi, edema dan apoptosis. Pengobatan farmakologis dengan menggunakan methylprednisolone bertujuan untuk mengurangi cedera sekunder (Gregory D, at.al., 2003).

Methylprednisolone merupakan neuroprotektif yang dipercaya sebagai terapi famakologis pada pasien dengan trauma spinal. Methylprednisolone sebagai neuroprotektif berkerja dengan cara menghambat paroxidasi lipid, influx calsium, mencegah ischemia, dan anti infalamsi. Meskipun banyak sekali penelitian telah dilakukan selama 40 tahun terakhir mengenai methylprednisolone sebagai neuroprotektif. Akan tetapi hingga saat ini masih kontroversial tentang penggunaan methylprednisolone pada trauma spinal (Kelly A. at.al., 2010). Oleh karena itu pada makalah ini akan membahas bagaimana seharusnya penggunaan terapi methylprednisolone pada kasus trauma spinal.

\section{Rumusan Masalah}

Berdasarkan latar belakang yang telah diuraikan, maka dikemukakan rumusan masalah sebagai berikut :

Bagaimanakah efektifitas penggunaan dosis tinggi methylprednisolon pada pasien dengan trauma spinal?

\section{Tujuan}

Makalah ini bertujuan untuk mengetahui bagaimana penggunaan methylprednisolon pada pasien dengan trauma spinal 


\section{TINJAUAN PUSTAKA}

\section{Patofiologi Acute Spinal Cord Injury}

Proses patologi yang terjadi pada pasien dengan trauma spinal dibagi menjadi dua tahap yaitu cedera primer dan cedera sekunder. Cedera primer disebabkan oleh trauma mekanik, compresi, contusio, laserasi, dan trauma penetrasi pada spinal cord. Kebanyakan kasus pasien dengan trauma spinal, cidera primer menyebabkan paralysis yang diakibatkan oleh kompresi dan contusio pada spinal cord atau berpindahnya collum spinal akibat fraktur atau dislokasi tulang pada spinal (Sekhon and Fehlings, 2001). Kerusakan akibat cedera primer menyebabkan cedera sekunder walaupun terjadinya dalam waktu menit sampai dengan bulan setelah cedera (Baptiste and Fehlings, 2006).

Cedera sekunder terjadi hal-hal sebagai berikut, peningkatan respirasi anerobik, peroxidasi lemak, kerusakan pada pembuluh darah, axon, dan myelin. Terjadi infalamsi akibat respon dari neutropil, microglia, dan magrofag. Pada cedera sekunder juga terjadi edema, peningkatan permiabilitas barier pembuluh darah pada spinal cord serta terjadi ischemia dan nekrosis. Sehingga apabila pasien dengan trauma spinal tidak ditangani dengan tepat dan cepat akan memperparah kondisi pasien. Terapi farmakologis dengan menggunakan methylprednisolon bertujuan untuk mencegah cedera sekunder akibat trauma (Komal A. et. al., 2010)

\section{Methylprednisolon}

Managemen trauma spinal dengan mengunakan methylprednisolon adalah untuk mencegah cedera sekunder akibat trauma telah dilakukan studi sejak lama sekali. Penggunaan dosis tinggi methylprednisolon akan mengambat peroxidasi lipid dengan menstabilkan membrana sel. Telah diketahui bahwa dengan mengambat peroxidasi lipid dapat mengurangi ischemia dan necrosis (Hall ED \& Springer JE 2004 dalam Kelly A. at.al., 2010).
Penggunaan dosis tinggi methylprednisolon menunjukan bahwa terdapat penurunan pelepasan interleukin, prostaglandin dimana merupakan mediator inflamasi. Manfaat yang lain dari penggunaan dosis tinggi methylprednisolon adalah meningkatkan perfusi ke jaringan yang mengalami cedera, menurunkan edema, peningkatan genarasi implus, dan efek positif pada konsentrasi elektrolit (Hawryluk GW, Rowland J, Kwon BK, Fehlings MG, 2008).

\section{PEMBAHASAN}

Penelitian mengenai terapi methylprednisolon pada trauma spinal telah banyak dilakukan. Seperti 3 penelitian dengan mengunakan sampel yang besar, desain penelitian yang handal, dan uji klinis yang dilakukan oleh National Acute Spinal Cord Injury Studies (NASCIS I, II dan III) meneliti tentang efek penggunaan terapi steroid terhadap pasien dengan trauma spinal (Bracken, et. al., 1984 dalam Hugenholtz, 2003).

Dalam NASCIS I meneliti tentang perubahan fungsi motorik pada spesifik otot dan perubahan pada sentuhan ringan. Hasilnya tidak ada perbaikan yang signifikan pada fungsi sensorik maupun motorik. Tidak ada perbaikan fungsi sensorik maupun motorik diduga karena dosis methylprednisolon kurang tinggi. Sehingga peneliti menyarankan untuk memberikan methylprednisolon dalam dosis tinggi (Hugenholtz, 2003).

Dalam NASCIS II yang dipublikasikan pada tahun 1990 membandingkan penggunaan dosis tinggi methylprednisolon $(30 \mathrm{mg} / \mathrm{kg}$ intravena bolus) dengan naloxon $(5,4 \mathrm{mg} / \mathrm{kg}$ bolus, kemudian dikuti 4,0 mg/kg/jam selam 23 jam) dan placebo pada 487 pasien dengan trauma spinal. Hasilnya adalah secara keseluruhan tidak ditemukan perbedaan yang signifikan fungsi neurologi pada semua kelompok. Akan tetapi setelah dilakukan analisis bagian/sub kelompok didapatkan bahwa pasien yang mendapatkan terapi methylprednisolon dalam 8 jam setelah 
cedera spinal menujukan bahwa terdapat perbaikan fungsi motorik dan sensorik dalam waktu 6 minggu dan 6 bulan. Setelah di follow up selama 1 tahun menunjukan bahwa terdapat perbaikan yang signifikan fungsi motorik sisi kanan. Tetapi tidak ada perbedaan pada fungsi sensorik dan tingkat kematian diantara kelompok (Hugenholtz, 2003., Komal A. et. al., 2010).

Dalam NASCIS III penelitian dilakukan pada 499 pasien dengan trauma spinal, membandingkan pemberian methylprednisolon dalam waktu 48 jam infus dengan 24 jam infus yang dimulai dalam waktu 8 jam setelah cedera. Hasilnya tidak perbaikan fungsi motorik maupun sensorik pemberian methylprednisolon dalam waktu 24 jam. Hanya setelah dilakukan post hoc pada pasien yang menerima methylprednisolon 48 jam infus terutama pemberiannya dimulai 3-8 jam setelah cedera (Hugenholtz, 2003., Komal A. et. al., 2010).

Sebuah meta-analisis dari semua studi menyimpulkan, atas dasar dari sub kelompok post hoc yang masih kontrovesi dalam NASCIS II dan III dimana data tersebut dari Jepang. Pemberian dosis tinggi methylprednisolon dalam waktu 8 jam setelah cedera menunjukan adanya perbaikan fungsi motorik dan sensorik. Meskipun metaanalisis mengenai keefektifan methylprednisolon sebagai terapi trauma spinal masih belum jelas dan membutuhkan penelitian/studi lebih lanjut (Hugenholt, 2003).

Terapi steroid bukan tanpa risiko/komplikasi. Kebanyakan pasien dengan trauma spinal yang mendapatkan terapi methylprednisolon mengalami kelainan kapasitas vital paru dan sepsis. Dalam semua studi NASCIS dan beberapa studi yang lainya didapatkan insiden sepsis dan pneumonia sangat tinggi pada pasien yang menerima terapi dosis tinggi methylprednisolon dari pada kelompok yang menerima placebo atau obat lain. Hiperglikemia dan komplikasi gastrointestinal juga terjadi pada pemberian dosis tinggi methylprednisolon (Hugenholtz, 2003., Komal A. et. al., 2010).

Biaya terapi infus metilprednisolon tidak menjadi penghalang untuk terapi pasien dengan trauma spinal. Keuntungan dari kekuatan anti-gravitasi pada satu atau lebih otot dibawah segmen tulang belakang dapat memberikan keutungan fungsional yang penting, terutama pada pasien dengan cervical spinal cord injury. Oleh karena itu, meskipun hanya ada perbaikan kecil subkelompok NASCIS dapat dipandang sebagai manfaat dalam kasus cedera tulang cervical lengkap atau tidak lengkap. Meskipun risiko komplikasi dalam subkelompok NASCIS kemungkinan tetap terjadi, dokter mungkin masih memilih untuk mengelola dosis tinggi metilprednisolon infus dalam waktu 8 jam setelah cedera (Hugenholt, 2003., Kelly A. et.al., 2010).

Berdasarkan penelitian yang ada sejak 40 tahun terakhir, permberian dosis tinggi metilprednisolon merupakan pilihan terapi pada pasien dengan trauma spinal. Pemberian dosis tinggi metilprednisolon yaitu $30 \mathrm{mg} / \mathrm{kg}$ bolus selama 15 menit, kemudian diikuti dengan 5,4 mg/kg/jam selama 23 jam, jika pemeberian metilphrednisolon dimulai 3 jam setelah cedera. Pertimbangkan terapi metilprednisolon dilanjutkan sampai 48 jam jika awal pemberiannya dalam 3 sampai 8 jam setelah cedera (Kelly A. et.al., 2010).

Hindari pemberian terapi metilprednisolon apabila lebih dari 8 jam setelah cedera. Berdasarkan studi yang telah dilakukan termasuk NASCIS I, II dan III tidak didapatkan hasil yang signifikan dalam perbaikan fungsi motorik maupun sensorik antara kelompok pasien yang mendapatkan terapi metilprednisolon dengan kelompok pasien yang menerima placebo atau obat yang lain (Kelly A. et.al., 2010).

Pasien yang mendapatkan terapi dosis tinggi metilprednisolon harus diobsevasi dengan intensive akan kompilkasi akibat terapi tersebut. Pasien harus mendapatkan cairan yang adekuat jika ada indikasi dan juga harus 
mendapat profilaksis ulser untuk mencegah komplikasi pada gastro intestinal. Pasien juga harus terhidar dari keaadan hiperglikemia agar tidak terjadi komplikasi seperti sepsis. Sehingga pemberian dosis tinggi metilprednisolon dapat maksimal dengan cara meningkatkan efek terapuetik dan meminilisir efek sampingnya (Kelly A. et.al., 2010).

\section{KESIMPULAN}

Metilprednisolon merupakan neouropritektif pada pasien dengan trauma spinal. Permberian dosis tinggi metilprednisolon merupakan pilihan terapi pada pasien dengan trauma spinal. Pemberian dosis tinggi metilprednisolon dalam waktu 8 jam setelah cedera pada pasien dengan trauma spinal dapat memberikan manfaat dalam menigkatkan fungsi motorik dan sensorik.

Pasien yang mendapatkan terapi dosis tinggi metilprednisolon harus diobservasi dengan intensive agar dapat mengurangi komplikasi akibat terapi tersebut.. Pemberian cairan harus adekuat, pencegahan komplikasi gastointestinal dengan pemberian profilaksis, dan mencegah terjadinya hiperglikemia agar pasien terhidar dari sepsis.

\section{DAFTAR PUSTAKA}

Baptiste and Fehlings(2006). Pharmacological Approaches To Repair the Injured Spinal Cord JOURNAL OF NEUROTRAUMA Volume 23, Number 3/4, 2006 Mary Ann Liebert, Inc. 318-334

Botelho RV et al, (2010). Effectiveness of methylprednisolone in acute spinal cord injury - a systematic review of random ized contro lled trials. Rev Assoc Med Bras 2009; 2010; 56(6): 729-37

DJ Short et al. (2000). High dose methylprednisolone in the management of acute spinal cord injury - a systematic review from a clinical perspective. International
Medical Society of Paraplegia All rights reserved 1362 - 4393/00.

Fawcett et al. (2007). Guidelines for the conduct of clinical trials for spinal cord injury as developed by the ICCP panel: spontaneous recovery after spinal cord injury and statistical power needed for therapeutic clinical trials. Spinal Cord (2007) 45, 190-205.

Gregory D, at.al., (2003). Efek of Methylprednisolon on regional blood flow and recovery of somatosensory evoked potentials. Journal of bone and join sugery. $2003 ; 85 ; 1$

Hugenholtz, (2003). Methylprednisolone for acute spinal cord injury: not a standard of care. Canadian Medical Association or its licensors. CMAJ. 29, 2003; 168 (9).

Hurlbert, (2000). Methylprednisolone for acute spinal cord injury: an inappropriate standard of care. $J$. Neurosurg: Spine / Volume 93 / July, 2000. Neurosurgical Forum, pp 175182.

Hall ED \& Springer JE (2004) Neuroprotection and acute spinal cord injury: a reappraisal. NeuroRX. 2004; 1(1):80-100.

Hawryluk GW, Rowland J, Kwon BK, Fehlings MG (2008) Protection and repair of the injured spinal cord: a review of completed, ongoing, and planned clinical trials for acute spinal cord injury. Neurosurg Focus. 2008; 25(5):E14.

Kelly A. at.al.,( 2010). High-Dose Methylprednisolone in Acute Spinal Cord Injuries: Proceed With Caution. orthopedics. APRIL 2010. volume 33. number 4

Komal A. et. al., (2010). High-Dose Methylprednisolone in Acute Spinal Cord Injuries: Proceed With Caution. may 2010. volume 33. number 5 . 
JURNAL ILMIAH KESEHATAN MEDIA HUSADA I VOLUME 02/ NOMOR 01/ SEPTEMBER 2013 